\title{
Development of materials to support parents whose babies cry excessively: findings and health service implications
}

\author{
Jaqui Long ${ }^{1, a}$, Charlotte Powell ${ }^{1, b}$, Deborah Bamber ${ }^{1, b}$, Rosemary Garratt ${ }^{1, c}$, Jayne Brown ${ }^{1, d}$, Sue Dyson ${ }^{2, d}$ \\ and lan St James-Roberts ${ }^{3, \mathrm{e}}$ \\ ${ }^{1}$ Nursing \& Midwifery Research Centre, De Montfort University \\ ${ }^{2}$ School of Health \& Education, Middlesex University \\ ${ }^{3}$ Thomas Coram Research Unit, UCL Institute of Education, University College London
}

\begin{abstract}
Aim: To develop evidence-based materials which provide information and support for parents who are concerned about their baby's excessive crying. As well as meeting these parents' needs, the aim was to develop a package of materials suitable for use by the UK National Health Service (NHS). Background: Parents report that around $20 \%$ of infants in Western countries cry excessively without an apparent reason during the first four months of age. Traditionally, research has focused on the crying and its causes. However, evidence is growing that how parents evaluate and respond to the crying needs to receive equal attention. This focus encompasses parental resources, vulnerabilities, well-being and mental health. At present, the UK NHS lacks a set of routine provisions to support parents who are concerned about their baby's excessive crying. The rationales, methods and findings from a study developing materials for this purpose are reported. Method: Following a literature review, 20 parents whose babies previously cried excessively took part in focus groups or interviews. They provided reports on their experiences and the supports they would have liked when their baby was crying excessively. In addition, they identified their preferred delivery methods and devices for accessing information and rated four example support packages identified by the literature review. Findings: During the period their baby cried excessively, most parents visited a health service professional and most considered these direct contacts to have provided helpful information and support. Websites were similarly popular. Telephones and tablets were the preferred means of accessing online information. Groups to meet other parents were considered an important additional resource by all the parents. Three package elements - a Surviving Crying website, a printed version of the website and a programme of Cognitive Behaviour Therapy-based support sessions delivered to parents by a qualified practitioner, were developed for further evaluation.
\end{abstract}

Key words: infant crying; parental mental health; parental well-being; parenting

Received 12 June 2017; revised 23 October 2017; accepted 19 November 2017;

first published online 10 January 2018

Correspondence to: Emeritus Professor, Ian St James-Roberts, Thomas Coram Research Unit, 27-28 Woburn Square, London WC1H 0AA, UK. Email: i.stjamesroberts@ucl.ac.uk

${ }^{a}$ Research Associate, School of Health \& Related Research, University of Sheffield.

${ }^{\mathrm{b}}$ Research Associate, Nursing \& Midwifery Research Centre, De Montfort University.

${ }^{\mathrm{c}}$ Reader in Midwifery, Nursing \& Midwifery Research Centre, De Montfort University.

${ }^{\mathrm{d}}$ Professor, Nursing \& Midwifery Research Centre, De Montfort University.

${ }^{\mathrm{e}}$ Emeritus Professor, Thomas Coram Research Unit, UCL Institute of Education, University College London. 


\section{Introduction}

Parents report that around $20 \%$ of infants in western countries cry a lot without an apparent reason during the first four months of age (Alvarez, 2004; Douglas and Hill, 2011; Wolke et al., 2017). Until recently, this crying was widely attributed to gastro-intestinal disorder and pain and known as 'infant colic' (Illingworth, 1954; Wessel et al., 1954). However, evidence has accumulated that most such infants are healthy and grow and develop normally (Stifter and Braungart, 1992; Lehtonen, 2001), that many normal infants have a crying 'peak' in the first three months of age (Barr, 1990; St James-Roberts and Halil, 1991; Wolke et al., 2017), and that this crying peak and the 'unsoothable' crying bouts which alarm parents usually resolve spontaneously by five months of age (Barr et al., 2005). This has led some reviews to conclude that the crying is usually due to normal developmental processes (Barr and Gunnar, 2000; St James-Roberts et al., 2013).

Alongside these findings, the term 'infant colic' has been criticised for failing to distinguish adequately between 'prolonged' infant crying (a measure of crying duration) and a parent's evaluation that their baby is crying too much and may be a sign that something is wrong with this baby ('excessive infant crying') (St James-Roberts, 2012). Although related, there is growing awareness that 'prolonged' and 'excessive' crying need to be distinguished, so that research into the crying is matched by an equal focus on its impact on parents (Zeifman and St James-Roberts, 2017). There is evidence, for instance, that crying judged to be excessive can trigger premature termination of breastfeeding (Howard et al., 2006), over-feeding (Stifter et al., 2011), parental distress and depression (Murray and Cooper, 2001; Kurth et al., 2011), poor parent-child relationships (Papousek et al., 2001), problems with long-term child development (Schmid and Wolke, 2014; Smarius et al., 2017) and infant abuse in a small number of cases (Barr et al., 2006). Yet, there are no routine, tried and tested, UK health services for supporting parents in managing infant crying. Instead, parents turn to popular books, magazines or websites, which give conflicting advice (Catherine et al., 2008), or take babies to clinicians or hospital Accident \& Emergency departments, although only around 5\% of such infants have an organic disturbance (Freedman et al., 2009).
By involving parents in the development of evidence-based materials they consider fit for purpose, this study aimed to take the first steps towards the provision of health care services which improve the well-being of parents whose babies cry excessively, their infants' outcomes, and how UK National Health Service (NHS) money is spent.

\section{Methods}

\section{Governance}

Study public registration no. ISRCTN84975637; ethical approval provided by De Montfort University (ref. 13450) and the NHS (IRAS project ID 152836); Research \& Development approval by Leicestershire Partnership NHS Trust (LPT). The study was regulated by a National Institute for Health Research (NIHR)-appointed Steering Committee and coordinated by a Management Group, including the research team, Senior LPT Health Visitors (HVs), a paediatrician, General Practitioner, health economist, members of Leicester Clinical Trials Unit and National Childbirth Trust (NCT), Cry-Sis and parent representatives.

\section{Literature review}

To identify evidence-based interventions to support parents who are concerned about their infant's excessive crying, a literature review was conducted updating an existing systematic review of this material (Douglas and Hill, 2011). The search strategies used are described in Appendix 1. Inclusion criteria were: the existence of the intervention materials in a published and exportable form; a cost which allowed potential adoption of the materials within the NHS; availability of at least provisional evidence of effectiveness.

Although excessive infant crying is often considered to be a paediatric condition, it can also be viewed as a stressor which may impact on adult well-being and mental health (Murray and Cooper, 2001; Kurth et al., 2011). The degree of impact is partly due to how parents cope with it, which is affected by underlying parental vulnerabilities, circumstances and resources (Laurent and Ablow, 2012; Smarius et al., 2016). To recognise this, the literature review was also used to search for evidence of interventions that were effective in supporting parental and adult coping and mental health, particularly in the postpartum period. 


\section{Recruiting parents}

In the United Kingdom, HVs provide universal primary care for parents with young babies and are the obvious choice for delivering the intended service within the NHS. With support from LPT managers collaborating in the study, HVs in five $\mathrm{HV}$ areas were invited to briefings about the study and to take part. In total, $55 \mathrm{HVs}$ gave written informed consent to collaborate with the study by referring parents who had been distressed by their baby's excessive crying to the research team. To widen recruitment, flyers were distributed via local NCT networks, children's centres, HV bases and parenting/baby groups to inform parents about the study.

Following initial contact, researchers explained the study to parents and sought their written informed consent to take part. Full eligibility criteria for parents were:

- Living in the LPT area;

- Previously having a healthy baby whose excessive crying in the first six months had caused concern for either parent;

- Their baby was no longer crying excessively;

- English speaking or supported by an English speaker.

Although translation into other languages was desirable, this was costly and local HV experience was that most non-English speaking parents were accompanied by English speaking family members or friends.

\section{Focus groups and interviews with the parents}

The recruited parents were asked to take part in a focus group, held in a local venue at a time convenient for parents. They were invited to bring their babies or children with them. Four focus groups, lasting $2-3 \mathrm{~h}$ and ranging in size from 2 to 5 parents, were held. Since mutually convenient times could not always be found, six parents were interviewed individually following the same format. In total, 20 parents (18 mothers; two fathers) took part. Two researchers experienced in focus group and interview methods facilitated each session, whilst two others made observational notes and provided informal child care. Sessions were audio-recorded for later verbatim transcription. Themes emerging from these qualitative data are reported elsewhere (Garratt et al., 2017).
Each focus group followed a planned structure, with two main parts. First, facilitators explained the group aims and procedures and participants introduced themselves, using pseudonyms if they wished to maintain anonymity. Parents were asked to describe their experience of having a baby who cried excessively, what was most challenging, who provided help, what was most helpful, what else might have helped, what sorts of supports they would have liked to have received at the time, and what routine services should include. They were asked what they considered the most suitable delivery method (website, leaflet, direct contact with a professional, telephone contact) and what devices they would prefer to use to access online information and support (computer, tablet, telephone).

In part two, materials from the four example support packages identified by the literature review were evaluated by the parents. All four packages included a website together, in some cases, with supplementary video or written materials. Sample materials from each package were shown to parents, with a changed presentation order for each session to reduce order effects. Appendix 1 gives more details. After each example, each parent was asked to give detailed feedback using five, 5-point rating scales:

(1) How attractive the materials were (very attractive - very unattractive);

(2) How clear was the information provided (very clear - very unclear);

(3) How helpful was the information provided (very helpful - very unhelpful);

(4) How much they liked each of 10 researchernominated features of the package (really liked - did not like);

(5) How important it was to include materials like these as part of NHS care (very important not at all important).

In addition, parents were invited to make written comments on other features they felt were important, disliked or could be improved.

Parents were asked to re-visit the four example support package websites after the focus group sessions. Follow-up telephone calls were used to confirm whether they had done so and whether this more extensive exposure had changed their opinions and ratings. Based on feedback from the focus groups, the follow-up contacts were also used to invite parents to contribute further to the 
package by consenting to the inclusion of their quotes from the focus group transcripts, written experiences and/or video presentations of their story, in the study materials. To recognise parents' contributions to the research, they were given $£ 50$ shopping vouchers on completing the focus groups and when they gave feedback on the developed package.

\section{Results}

\section{Literature review}

Appendix 1 provides a detailed description of the literature review process. Four example packages which met the study criteria, were identified:

\section{http://purplecrying.info/}

www.whatwerewethinking.org.au

http://www.copingwithcrying.org.uk

http://raisingchildren.net.au/articles/cry_baby_ program.html/context/255

Contracts with the organisations involved were arranged to allow these materials to be included in the study focus groups. A Rhode Island USA programme which requires a multi-professional clinic was excluded because it is costly and difficult to export (Twomey et al., 2012).

The literature review also found that Cognitive Behaviour Therapy (CBT)-based interventions are effective in helping adults, including parents in the postpartum period, to cope with stressful conditions and moderate psychological distress (Morell et al., 2009; Dennis and Dowswell, 2013; Chowdhary et al., 2014; Stein et al., 2014). Use of programmes of this type for this purpose is recommended by the UK National Institute for Health \& Care Excellence (NICE, 2009, 2014).

\section{Focus group data}

Table 1 presents demographic figures for the participating parents and their babies. Most were contacted by HVs, but five were recruited via NCT networks, flyers or other parents. Two of the 20 parents were fathers participating with female partners, but only one father provided demographic data (see Table 1 footnote). Most parents had experienced just one excessively crying baby but one mother had experienced two and described both, giving data for 19 babies in all.
Table 1 Demographic characteristics of focus group parents and their babies

\begin{tabular}{|c|c|c|}
\hline & $\mathrm{n}$ & $\%$ \\
\hline \multicolumn{3}{|l|}{ Parental gender $(n=20)$} \\
\hline Female & 18 & 89.5 \\
\hline Male ${ }^{a}$ & 2 & 10.5 \\
\hline \multicolumn{3}{|l|}{ Maternal ethnicity $(n=18)$} \\
\hline English/Welsh/Scottish/Northern Irish/British & 13 & 72.2 \\
\hline White/Black Caribbean mixed & 1 & 5.6 \\
\hline Indian & 1 & 5.6 \\
\hline Bangladeshi & 1 & 5.6 \\
\hline Pakistani & 1 & 5.6 \\
\hline Any other mixed ethnic background & 1 & 5.6 \\
\hline \multicolumn{3}{|l|}{ Mothers' highest educational level $(n=18)$} \\
\hline Postgraduate degree/qualification & 5 & 27.8 \\
\hline Undergraduate degree & 6 & 33.3 \\
\hline Higher post-A level vocational qualification & 1 & 5.6 \\
\hline A level/NVO level 3 & 3 & 16.7 \\
\hline GCSE/O level/NVQ level 2/BTEC diploma & 2 & 11.2 \\
\hline Completed secondary school education & 1 & 5.6 \\
\hline \multicolumn{3}{|l|}{$\begin{array}{l}\text { Mothers' employment status in the period } \\
\text { when baby cried excessively }(n=18)\end{array}$} \\
\hline Maternity leave from full-time employment & 6 & 33.3 \\
\hline Maternity leave from part-time employment & 1 & 5.6 \\
\hline Self employed & 1 & 5.6 \\
\hline part-time & 5 & 27.8 \\
\hline oking for work & 2 & 11.1 \\
\hline Not in paid employment & 3 & 16.7 \\
\hline \multicolumn{3}{|l|}{$\begin{array}{l}\text { Mothers' marital and living arrangements in the } \\
\text { period when baby cried excessively }(n=18)\end{array}$} \\
\hline Married or living with partner & 15 & 83.3 \\
\hline ported by partner & 1 & 5.6 \\
\hline Single $p$ & 1 & 5.6 \\
\hline Unknown & 1 & 5.6 \\
\hline \multicolumn{3}{|l|}{ Baby's gender $(n=19)$} \\
\hline Male & 9 & 47.4 \\
\hline Female & 10 & 52.6 \\
\hline \multicolumn{3}{|l|}{ Baby's birth order $(n=19)$} \\
\hline First-born & 10 & 53 \\
\hline $\mathrm{Sec}$ & 8 & 42 \\
\hline Third-born & 1 & 5 \\
\hline \multicolumn{3}{|l|}{$\begin{array}{l}\text { Baby's feeding method when started crying } \\
\text { excessively }(n=19)\end{array}$} \\
\hline Breast milk only & 7 & 36.8 \\
\hline Breast plus formula milk & 6 & 32.6 \\
\hline Formula only & 6 & 32.6 \\
\hline \multicolumn{3}{|l|}{$\begin{array}{l}\text { Baby's health in the period when he/she cried } \\
\text { excessively }(n=19)\end{array}$} \\
\hline Baby had a fever & 0 & 0 \\
\hline Baby seemed unwell & 2 & 10.5 \\
\hline Concerns about baby's weight gain & 1 & 5.3 \\
\hline Baby had problems feeding & 11 & 57.9 \\
\hline $\begin{array}{l}\text { Baby's feeding checked by a health } \\
\text { professional }\end{array}$ & 17 & 89.5 \\
\hline $\begin{array}{l}\text { Baby's weight checked by a health } \\
\text { professional }\end{array}$ & 19 & 100 \\
\hline \multicolumn{3}{|l|}{$\begin{array}{l}\text { Baby's age when the excessive crying started } \\
\text { and stopped }(n=19)\end{array}$} \\
\hline Started (median/range in weeks) & & $1 / 0-9$ \\
\hline Stopped (median/range in weeks) & & 19/8.5-104 \\
\hline $\begin{array}{l}\text { Length of excessive crying (median/range in } \\
\text { weeks) }\end{array}$ & & $18 / 4-100$ \\
\hline
\end{tabular}

${ }^{a}$ Both dads provided data, but only one provided demographic information. He was white British, 42 years old with a postgraduate degree qualification. 
As Table 1 shows, most mothers were white British $(73 \%)$, had an undergraduate or postgraduate degree $(61 \%)$ and were married or living with a partner $(83 \%)$ at the time when their baby cried excessively. The mothers' average age was 30.4 years, ranging from 19 to 41 years. Nearly half of the babies were second or third-born, with 8 of the 18 families having other children who had not cried excessively. The babies were equally likely to be boys or girls, and they were almost equally divided between breast, formula or mixed feeding when the crying started. None had a fever and only two seemed unwell. Although $58 \%$ of their mothers reported that their baby had problems with feeding, all the babies had been checked by clinicians for weight gain and $89 \%$ for feeding problems, without any specific problem being confirmed.

Typically, the babies' excessive crying started at around 1 week and stopped by 5 months of age. However, the variability in how long the crying lasted was substantial, ranging from 4 to 100 weeks.

Table 2 summarises the 20 parents' reports about sources of information and support. During the period when their baby was crying excessively, $89 \%$ of parents visited a HV, doctor or other health professional, $50 \%$ spoke with a health professional over the telephone, and $89 \%$ considered these to be effective sources. Websites were similarly popular, being consulted by $80 \%$ of parents, valued by all 20 parents, and considered an effective way to communicate information by $89 \%$. Most parents $(78 \%)$ preferred to access online information through their mobile phone, $44 \%$ via tablets (some preferred these equally). Most considered leaflets to be helpful $(72 \%)$ and effective in communicating information (76\%), but just $45 \%$ had used them during the period when their baby was crying excessively. All parents considered that groups to meet other parents with excessively crying babies would offer a valuable additional source of information and support.

All four example support packages shown to parents in the focus groups were rated attractive or very attractive, clear or very clear and helpful or very helpful by the majority (range 11-20) of parents. All 20 parents reported it was important that materials like these should be included as part of routine NHS care. Because our aim was to identify which features parents judged to be needed in future materials (not to compare existing examples). Tables 3 and 4 summarise the features parents liked
Table 2 Sources of information and support

\begin{tabular}{|c|c|}
\hline $\begin{array}{l}\text { Sources used by the parents when } \\
\text { their baby cried excessively } \\
(n=20)\end{array}$ & $\begin{array}{l}\text { No. (\%) parents used } \\
\text { this source }\end{array}$ \\
\hline Leaflets & $9(45)$ \\
\hline Maqazines & $4(20)$ \\
\hline Books & $7(35)$ \\
\hline Websites & $16(80)$ \\
\hline Phone Apps & $5(25)$ \\
\hline $\begin{array}{l}\text { Phone conversations with HV, } \\
\text { doctor or other health service } \\
\text { professional }\end{array}$ & $10(50)$ \\
\hline $\begin{array}{l}\text { Visits to speak with HV, doctor } \\
\text { or other health professional } \\
(n=19)\end{array}$ & $17(89)$ \\
\hline Online discussion board & $10(50)$ \\
\hline $\begin{array}{l}\text { Other sources of information or } \\
\text { support }\end{array}$ & $4(20)$ \\
\hline $\begin{array}{l}\text { Sources parents would have } \\
\text { found most helpful when their } \\
\text { baby cried excessively }(n=20)\end{array}$ & $\begin{array}{l}\text { No. (\%) parents would } \\
\text { have liked this a lot }\end{array}$ \\
\hline Extra visits from HV & $14(78)$ \\
\hline Extra phone calls from HV & $11(61)$ \\
\hline Leaflets & $13(72)$ \\
\hline Websites & $18(100)$ \\
\hline Online activities to complete & $4(25)$ \\
\hline Online discussion boards & $13(72)$ \\
\hline Facebook & $11(65)$ \\
\hline Group to meet other parents & $18(100)$ \\
\hline $\begin{array}{l}\text { Devices parents currently use to } \\
\text { access the internet }(n=18)^{\mathrm{a}} \\
\text { Desktop computer } \\
\text { Laptop or workbook } \\
\text { Tablet } \\
\text { Phone }\end{array}$ & $\begin{array}{l}\text { No. (\%) parents used } \\
\text { this device } \\
2(11) \\
12(67) \\
13(72) \\
17(94)\end{array}$ \\
\hline $\begin{array}{l}\text { Preferred device for accessing the } \\
\text { internet }(n=18)^{\mathrm{a}} \\
\text { Desktop computer } \\
\text { Laptop or workbook } \\
\text { Tablet } \\
\text { Phone }\end{array}$ & $\begin{array}{l}\text { No. (\%) parents } \\
\text { preferred this device } \\
2(11) \\
1(9) \\
8(44) \\
14(78)\end{array}$ \\
\hline $\begin{array}{l}\text { Best format for presenting } \\
\text { information to parents }(n=20)\end{array}$ & $\begin{array}{l}\text { No. (\%) parents rated } \\
\text { this effective or highly } \\
\text { effective }\end{array}$ \\
\hline $\begin{array}{l}\text { Leaflets from HV, doctor or } \\
\text { hospital }\end{array}$ & $13(76)$ \\
\hline Websites & $16(89)$ \\
\hline Phone Apps & $14(82)$ \\
\hline $\begin{array}{l}\text { Phone conversation with HV, } \\
\text { doctor or other health } \\
\text { professional }\end{array}$ & $13(76)$ \\
\hline $\begin{array}{l}\text { Visit to speak with HV, doctor or } \\
\text { other health professional }\end{array}$ & $16(89)$ \\
\hline
\end{tabular}

$\mathrm{HV}=$ health visitor.

a Two parents did not provide this information. Parents could use or prefer more than one device.

in at least one website. All 10 researcher-nominated features were liked or really liked. Features parents added in their written comments (Table 4) included accessible, relevant information; practical advice; an attractive, easy to use format; and offering reassurance to parents about their baby's crying. 
Table 3 Parents' ratings of researcher-nominated features of the four sample websites $(n=20)$

\begin{tabular}{|c|c|c|c|c|}
\hline & $\begin{array}{l}\text { Liked or } \\
\text { really liked }\end{array}$ & $\begin{array}{l}\text { Thought } \\
\text { was OK }\end{array}$ & $\begin{array}{l}\text { Neither liked or } \\
\text { disliked }\end{array}$ & Missing \\
\hline Practical suggestions & 20 & & & \\
\hline $\begin{array}{l}\text { Reassurance that I wasn't doing anything } \\
\text { wrong/ it wasn't my fault }\end{array}$ & 20 & & & \\
\hline That I could trust what they said & 20 & & & \\
\hline Other parents' experiences and ideas & 20 & & & \\
\hline Expert opinion and advice & 19 & 1 & & \\
\hline That the information is aimed at both parents & 20 & & & \\
\hline Videos & 18 & 1 & 1 & \\
\hline Workbooks & 18 & 2 & & \\
\hline $\begin{array}{l}\text { Interactive materials - responsive to your } \\
\text { interests and concerns }\end{array}$ & 17 & 1 & & 2 \\
\hline $\begin{array}{l}\text { That the materials were easy to access when } \\
\text { you need them }\end{array}$ & 20 & & & \\
\hline
\end{tabular}

Table 4 Features parents added in their written comments $(n=20)$

\begin{tabular}{|c|c|}
\hline & $\begin{array}{l}\text { Number o } \\
\text { parents }\end{array}$ \\
\hline \multicolumn{2}{|l|}{ Information } \\
\hline Relevant, easily accessible not too in- depth & 11 \\
\hline \multicolumn{2}{|l|}{ Clear and easy format } \\
\hline Clear, simple and easy to use format, able to find and understand information when needed & 10 \\
\hline \multicolumn{2}{|l|}{ Practical } \\
\hline Practical tips, advice and suggestions of strategies both for soothing the baby and coping tips for parents & 9 \\
\hline Gave reassurance & \\
\hline $\begin{array}{l}\text { Materials that took the crying seriously and acknowledged that sometimes babies do just cry } \\
\text { Includes other parents experiences }\end{array}$ & 7 \\
\hline Other parents' experiences as they could identify with them, eg, case studies & 4 \\
\hline \multicolumn{2}{|l|}{ Dads and Mums } \\
\hline Information that was relevant to Dads as well as Mums & 3 \\
\hline \multicolumn{2}{|l|}{ Couples } \\
\hline $\begin{array}{l}\text { Parents liked the fact that the materials gave information for couples, ways for parents to support } \\
\text { each other and work together }\end{array}$ & 2 \\
\hline \multicolumn{2}{|l|}{ Items specific to certain packages } \\
\hline $\begin{array}{l}\text { Specific items in the materials that parents liked included coping skills, videos and audio files and } \\
\text { websites that were interactive }\end{array}$ & 8 \\
\hline \multicolumn{2}{|l|}{ Focused } \\
\hline Focused specifically on uncontrollable, unsoothable crying & 1 \\
\hline
\end{tabular}

Twelve of the 20 parents were successfully recontacted after the focus groups. Eight had revisited one or more of the example websites. None wished to amend the responses given within the focus groups.

\section{Production of a set of parental support materials}

Reflecting the literature review and focus group data, three package elements were developed: a
Surviving Crying website; a printed version of the website materials; and a programme of CBT-based support sessions delivered directly to parents by a qualified practitioner.

A commercial marketing and communications agency was appointed to assist in developing the website materials. Their brief included preparing templates for the website design and layout, incorporating text, pictures and video materials prepared by the study team, setting up and testing 
the website for compatibility with different devices and operating systems, hosting and maintaining the website and setting up Google Analytics to allow figures for website access by parents, HVs and visitors to be obtained.

The website materials were uploaded by the study team, using an iterative process of drafting and revision, taking account of the focus group findings. Care was taken to ensure that all advice was evidence-based and a section listing sources was included. The text was adjusted to a reading age of 9-12 years. With parents' permission, three videos of parents speaking about their experiences and five written stories were uploaded onto the website with names changed to maintain anonymity, together with three videos of professionals providing information and guidance.

The draft website materials were shown or sent to the 20 focus group parents for review (16 provided feedback) and were circulated to HVs for approval, checked for clinical accuracy by the study paediatrician, and revised as necessary. Figure 1 shows the home page of the resulting Surviving Crying website as it appears on phone, tablet, laptop and desktop computer screens. The website remains copyright and requires a login and password.

Following the website design and content so far as possible, a printed version of the materials was prepared as a booklet.

Based on prior CBT studies (NICE, 2009, 2014; Tandon et al., 2011; Alexander, 2013) and the longitudinal course of infant crying, a programme of practitioner CBT support was designed to include up to five sessions, each lasting 60-90 min, delivered to parents in person or by telephone within a 4-6-week period. The sessions could be delivered at home or in a local centre, according to parents' wishes. Depending on the availability of

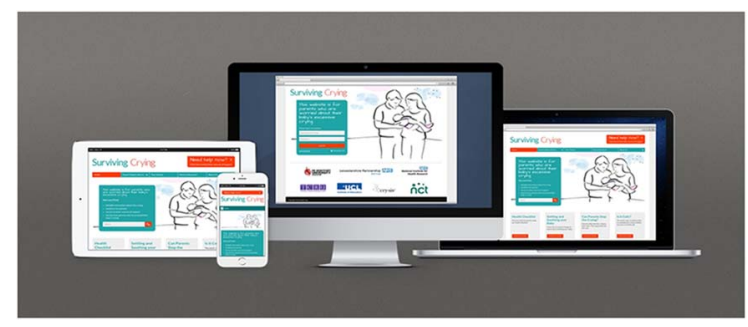

Figure 1 The Surviving Crying home page as it appears on various devices other parents, parents could choose whether to take part in one-to-one or small-group sessions.

Three key topics were included in each practitioner-delivered session:

- Assessing infant crying and well-being, making arrangements to obtain any other information or support needed, and providing parents with information and reassurance.

- Monitoring the soothing and baby-care methods parents were using.

- Supporting parents in developing coping strategies which helped them to manage their own emotions and actions and enhance their wellbeing.

A practitioner manual for delivering the CBT programme was prepared by the study team in collaboration with a CBT-qualified counselling psychologist with extensive experience in supporting adult mental health in the NHS. The manual underwent iterative revisions, was piloted, and then checked by parent and HV members of the Study Management Group. The adopted version included practitioner guidance and record sheets as well as materials for parents.

\section{Safeguarding procedures}

Together with the LPT safeguarding officers, clinical staff and the study paediatrician, the study team developed safeguarding protocols to ensure the safety of parents and babies involved in the study.

\section{Methods for evaluating the package materials}

Measures of participation and cost, questionnaires assessing infant crying, feeding and health, parental well-being and crying knowledge, together with rating scales to evaluate each element of the support package, were developed. To avoid duplication, these methods will be described together with the evaluation findings when available.

\section{Discussion}

Stage 1 of the Surviving Crying study, reported here, was designed to develop a new, evidencebased, package of materials to support parents who are concerned about their baby's excessive 
crying. The term 'excessive infant crying' refers to a parent's evaluation that their baby is crying too much and may be a sign that something is wrong with this baby, as opposed to 'prolonged crying' which implies a measure of crying duration.

Based on a literature review, four example support packages met study criteria and were selected for inclusion in the study. The review also showed that CBT-based interventions are effective in helping adults, including parents in the postpartum period, to cope with stressful conditions and moderate psychological distress, anxiety and depression.

In total, 20 parents whose babies had cried excessively in the first six months of infancy took part in focus groups or interviews designed to obtain information about the sorts of parental supports needed and to evaluate the example support packages. This small number of parents and their demographic characteristics - they were predominantly white, well-educated and living with partners in stable relationships, while only two were fathers - are limitations of the study which need to be taken into account when interpreting the findings. Inclusion of larger and more culturally diverse groups in future studies will indicate whether the findings apply to different communities and identify any improvements to the support package which need to be made.

Several findings were, however, highly consistent across the parents who participated. First, they had used and rated two sources of support direct contact with a health service professional and a website providing information and guidance - very highly. Other sources, including telephone contacts and online discussion forums, were valued by around half or more parents. Notably, a large majority of parents wished to access the online material on their mobile phones. Leaflets, arguably the most common source of information in the NHS, were considered valuable by most parents, but fewer had used them when their baby was crying excessively. All 20 participants identified the need for groups to meet other parents as a source of information and support.

The parents' evaluations of the four example support packages provided evidence about features the parents liked and did not like. Features they liked or very much liked included providing clear and relevant practical information and guidance, reassurance, trustworthiness, that information was aimed at both parents, and the use of videos. Other parents' experiences and ideas, and expert advice, were also highly valued.

As well as a Surviving Crying website and printed version, a programme of CBT-based sessions for direct delivery to parents by a qualified professional was developed, together with a manual for delivering the programme. In addition to monitoring infant crying, baby-care and soothing strategies, the programme aimed to support parents in developing coping strategies which manage their own emotions and actions and enhance their well-being.

The study focused on parents, but some parental report data about their baby's crying were collected. The onset age for their crying (median 1 week) and age at which it stopped (median 19 weeks) are broadly in line with previous studies and the evidence that infant crying peaks in the first few months of age (Barr, 1990; St JamesRoberts, 2012; Wolke et al., 2017). However, variability between infants in the age at which the crying stopped (range 8.5-104 weeks), and how long the crying lasted (range 4-100 weeks) was substantial. Although accuracy varies, studies have found moderate to good agreement between parental reports and objective measures of infant crying (Barr et al., 1988; 1992; St James-Roberts et al., 1993; 1996). Furthermore, although most babies reported to cry excessively have normal outcomes, those reported to do so beyond four months of age are at risk for long-term developmental and behavioural problems (Wolke et al., 2002; Schmid and Wolke, 2014). These findings emphasise the need for NHS services which provide parents, particularly in vulnerable circumstances, with information and support.

In keeping with previous research, too, the majority of parents $(58 \%)$ reported that their baby had feeding problems (Catherine et al., 2008). However, almost all (89\%) infants had been checked for feeding difficulties, and all had been checked for weight gain, by a health professional, without confirming these as a problem. At the time of crying, just two of the 19 infants were judged unwell and one to be failing to gain enough weight. Although some researchers link unsettled behaviour in early infancy to feeding difficulties (Douglas and Hill, 2011), the evidence remains unclear and is likely to remain so until tests capable of distinguishing feeding, digestive and other organic causes are developed (Sung and St James-Roberts, 2017). 
Taken altogether, these findings identify an unmet need in UK National Health Services and provide evidence of the sorts of services parents would like to have available. Stage two of the study, involving a preliminary evaluation of whether the Surviving Crying materials are cost-effective and suitable for this purpose, is underway.

\section{Acknowledgements}

The authors thank the families who participated, the NIHR HTA Programme for its support, the staff of Leicestershire Partnership NHS Trust (LPT) for their assistance, and our Steering Committee and Management Group for their guidance. In particular, the study could not have taken place without the help of the following LPT staff: Nicy Turney, FiHV, Professional Lead Health Visiting, Families Young People and Children Services; Joanne Chessman, Clinical Team Leader; Gail Melvin, Research Manager; Joanna McGarr, Trainee Research Assistant; Lynn Hartwell, Research Nurse; the many HVs who took part. Consider Creative provided expert professional assistance in the development of the Surviving Crying website. The authors also thank other UK collaborators: Dr Elaine Boyle, University of Leicester; Charlie Owen, University College London; Sally Rudge, Counselling Psychologist \& CBT Practitioner; Rachel Plachcinski, National Childbirth Trust; Jan and John Bullen, Cry-Sis. Four university or charity research groups gave permission to evaluate their parental support materials during the study and the authors are grateful to them and their institutions for this support: Ron and Marilyn Barr for the PURPLE Crying Programme; Harriet Hiscock and Fallon Cook of Murdoch Children's Research Institute for Cry Baby; Jane Fisher and Heather Rowe, Monash University, for What Were We Thinking; Denise Coster and Peter Richards of the National Society for Prevention of Cruelty to Children, for Coping with Crying.

De Montfort University acknowledges the support of the National Institute of Health Research Clinical Research Network.

\section{Disclaimer}

This report presents independent research commissioned by the National Institute for Health Research (NIHR). The views and opinions

Primary Health Care Research \& Development 2018; 19: 320-332 expressed by authors in this publication are those of the authors and do not necessarily reflect those of the NHS, the NIHR, MRC, CCF, NETSCC, the HTA Programme or the Department of Health.

\section{Financial Support}

This research was funded by Grant no. 12-150-04 from the National Institute for Health Research HTA Programme.

\section{Conflicts of Interest}

None.

\section{References}

Alexander, P. 2013: CBT support groups for postnatal depression. Nursing Times 109, 12-14.

Alvarez, M. 2004: Caregiving and early infant crying in a Danish community. Journal of Developmental \& Behavioral Pediatrics 2, 91-98.

Arksey, H. and O'Malley, L. 2005: Scoping studies: towards a methodological framework. International Journal of Research Methodology 8, 19-32.

Barr, R.G. 1990: The normal crying curve: what do we really know? (Annotation). Developmental Medicine and Child Neurology 32, 356-62.

Barr, R.G. and Gunnar, M.R. 2000: Colic: the 'transient responsivity' hypothesis. In Barr, R.G., Hopkins, B. and Green, J.A., editors Crying as a sign, a symptom, \& a signal. London: Mac Keith Press/Cambridge University Press.

Barr, R.G., Kramer, M.S., Boisjoly, C., Mcvey-White, L. and Pless, I.B. 1988: Parental diary of infant cry and fuss behaviour. Archives of Disease in Childhood 63, 380-87.

Barr, R.G., Paterson, J., Macmartin, L., Lehtonen, L. and Young, S. 2005: Prolonged and unsoothable crying bouts in infants with and without colic. Journal of Developmental and Behavioral Pediatrics 26, 14-22.

Barr, R.G., Rotman, A., Vamengo, J., Leduc, D. and Francoeur, T.E. 1992: The crying of infants with colic: a controlled empirical description. Pediatrics 90, 14-21.

Barr, R.G., Trent, R.B. and Cross, J. 2006: Age-related incidence curve of hospitalized Shaken Baby Syndrome cases: convergent evidence for crying as a trigger to shaking. Child Abuse and Neglect 30, 7-16.

Catherine, N.L.A., Ko, J.J. and Barr, R.G. 2008: Getting the word out: advice on crying and colic in popular parenting magazines. Journal of Developmental and Behavioral Pediatrics 29, 508-11.

Chowdhary, N., Sikander, S., Atif, N., Singh, N., Fuhr, D.C., Rahman, A. and Patel, V. 2014: The content and delivery of psychological interventions for perinatal depression by nonspecialist health workers in low and middle income 
countries: a systematic review. Best Practice \& Research in Clinical Obstetrics and Gynaecology 28, 113-33.

Dennis, C.L. and Dowswell, T. 2013: Psychosocial \& psychological interventions for preventing postpartum depression. Cochrane Database of Systematic Reviews, Issue 2, Art. No. CD001134. https://doi.org/10.1002/14651858. CD001134.pub3.

Douglas, P. and Hill, P. 2011: Managing infants who cry excessively in the first few months of life. BMJ 343, 1265-69.

Fisher, J.R.W., Wynter, K.H. and Rowe, H.J. 2010: Innovative psycho-educational program to prevent common postpartum mental disorders in primiparous women: a before and after controlled study. BMC Public Health 10, 432.

Freedman, S.B., Al-Harthy, N. and Thull-Freedman, J. 2009: The crying infant: diagnostic testing and frequency of serious underlying disease. Pediatrics 123, 841-48.

Garratt, R., Powell, C., Bamber, D., Long, J., Dyson, S. and Brown, J. 2017: Parents' experiences of having an excessively crying baby (In Submission).

Howard, C.R., Lanphear, N., Lanphear, B.P., Eberly, S. and Lawrence, R.A. 2006: Parental responses to infant crying and colic: the effect on breastfeeding duration. Breastfeeding Medicine 1, 146-55.

Illingworth, R.S. 1954: Three-months' colic. Archives of Disease in Childhood 29, 165-74.

Kurth, E., Kennedy, H.P., Spichiger, E. and Stutz, E.Z. 2011: Crying babies, tired mothers: what do we know? A systematic review. Midwifery 27, 187-94.

Laurent, H.K. and Ablow, J.C. 2012: A cry in the dark: depressed mothers show reduced neural activation to their own infant's cry. Social, Cognitive and Affective Neuroscience 7, 125-34.

Lehtonen, L. 2001: From colic to toddlerhood. In Barr, R.G., St James-Roberts, I. and Keefe, M., editors New evidence on unexplained early infant crying: its origins, nature and management. Skillman, NJ: Johnson \& Johnson Pediatric Institute, 259-72.

Morell, C.J., Slade, P., Warner, R., Paley, G., Dixon, S., Walters, S.J., Brugha, T., Barkham, M., Parry, G.J. and Nicholl, J. 2009: Clinical effectiveness of health visitor training in psychologically informed approaches for depression in postnatal women: pragmatic cluster randomised trial in primary care. BMJ 338, a3045https://doi.org/10.1136/bmj. a3045.

Murray, L. and Cooper, P. 2001: The impact of irritable infant behavior on maternal mental state: a longitudinal study and a treatment trial. In Barr, R.G., St James-Roberts, I. and Keefe, M.R., editors New evidence on unexplained early infant crying: its origins, nature and management. Skillman, NJ: Johnson \& Johnson Pediatric Institute, 149-64.

NICE 2009: CG 90: Depression in adults: recognition and management. https://www.nice.org.uk/guidance/CG90.

NICE 2014: CG192: Antenatal and postnatal mental health: clinical management and service guidance. https://www. nice.org.uk/guidance/CG192.
Papouŝek, M., Wurmser, H. and von Hofacker, N. 2001: Clinical perspectives on unexplained early crying: challenges and risks for infant mental health and parentinfant relationships. In Barr, R.G., St James-Roberts, I. and Keefe, M.R., editors New evidence on unexplained early infant crying: its origins, nature and management. Skilman, NJ: Johnson \& Johnson Pediatric Institute, 289-316.

Schmid, G. and Wolke, D. 2014: Preschool regulatory problems and attention-deficit/hyperactivity and cognitive deficits at school age in children born at risk: different phenotypes of dysregulation? Early Human Development 90, 399-405.

Smarius, L.J.C.A., Strieder, T.G., Loomans, E.M., Doreleijers, T.A., Vrijkotte, T.G., Gemke, R.J. and van Eisden, M. 2017: Excessive infant crying doubles the risk of mood and behavioral problems at age 5: evidence for mediation by maternal characteristics. European Child \& Adolescent Psychiatry, 26, 293-302.

Stein, A., Pearson, R.M., Goodman, S.H., Rapa, E., Rahman, A., McCallum, M., Howard, L.M. and Pariente, C.M. 2014: Effects of perinatal mental disorders on the fetus and child. Lancet 384, 1800-1819.

St James-Roberts, I. 2012. The origins, prevention and treatment of infant crying and sleeping problems: an evidence-based guide for healthcare professionals and the families they support. London: Routledge.

St James-Roberts, I. and Halil, T. 1991: Infant crying patterns in the first year: normal community and clinical findings. Journal of Child Psychology and Psychiatry 32, 951-68.

St James-Roberts, I., Alvarez, M. and Hovish, K. 2013: Emergence of a developmental explanation for prolonged crying in 1- to 4-month-old infants: review of the evidence. Journal of Pediatric Gastroenterology and Nutrition 57, S30-S35.

St James-Roberts, I., Conroy, S. and Wilsher, K. 1996: Bases for maternal perceptions of infant crying and colic behaviour. Archives of Disease in Childhood 75, 375-84.

St. James-Roberts, I., Hurry, J. and Bowyer, J. 1993: Objective confirmation of crying durations in infants referred for excessive crying. Archives of Disease in Childhood 68, $82-84$.

Stifter, C.A., Anzman-Frasca, S., Birch, L.L. and Voegtline, K. 2011: Parent use of food to soothe infant/toddler distress and child weight status. An exploratory study. Appetite 57, 693-99.

Stifter, C.A. and Braungart, J. 1992: Infant colic: a transient condition with no apparent effects. Journal of Applied Developmental Psychology 13, 447-62.

Sung, V. and St James-Roberts, I. 2017: Infant colic. In Faure, C., Thapar, N. and DiLorenzo, C., editors Pediatric neurogastroenterology. New York: Springer, 369-79.

Tandon, S.D., Perry, D.F., Mendelson, T., Kemp, K. and Leis, J.A. 2011: Preventing perinatal depression in lowincome home visiting clients: a randomised controlled trial. Journal of Consulting and Clinical Psychology 79, 707-12. 
Twomey, J.E., High, P. and Lester, B.M. 2012: Colic: what's maternal health got to do with it? Infant Mental Health Journal 33, 543-52.

Wessel, M.A., Cobb, J.C., Jackson, E.B., Harris, G.S. and Detwiler, A.C. 1954: Paroxysmal fussing in infancy, sometimes called colic. Pediatrics 14, 421-35.

Wolke, D., Rizzo, P. and Woods, S. 2002: Persistent infant crying and hyperactivity problems in middle childhood. Pediatrics 109, 1054-60.

Wolke, D., Bilgin, A. and Samara, M. 2017: Systematic review and meta-analysis: fussing and crying durations and prevalence of colic in infants. Journal of Pediatrics 185, 55-61.

Zeifman, D. and St James-Roberts, I. 2017: Parenting the crying infant. Current Opinion in Psychology 15, 149-54.

\section{Appendix 1: Literature review strategy}

\section{Aims}

As part of the process of developing the intervention for this study, a focused literature review was undertaken with two aims:

- to identify recent evidence of existing interventions to support parents of babies considered to be crying excessively;

- to select a number of these interventions to show to parents attending focus groups in order to gain their feedback.

\section{Strategy}

The review was designed to update Douglas and Hill's (2011) systematic review concerning the causes of, and interventions to manage, term infants who cry excessively in the first few months of age. For the purposes of this review, 'excessive crying' was taken to mean any crying behaviour that parents considered problematic. Whilst a full systematic review could not be undertaken within the project's resources, all relevant research needed to be considered. A review strategy was drawn up based on Arksey and O'Malley's (2005) framework for a scoping study.

The review question was identified as: What support is available to parents with an excessively crying baby who is six months or under and who is otherwise well?

\section{Eligibility criteria Population}

Primary Health Care Research \& Development 2018; 19: 320-332
Parents of excessively crying babies up to six months, where no medical reason for the crying had been identified. Based on the evidence that the term 'colic' is often applied to unsoothable crying, babies described as having colic were included.

Parents of babies over six months were excluded to rule out sleep problems and other issues that arise at older ages. Premature babies or those medically diagnosed as unwell were also excluded as constituting a different population with a given reason for the crying, and potentially different needs. Medically diagnosed feeding problems were excluded for similar reasons.

Interventions for parents with diagnosed physical or mental health problems were excluded, apart from those experiencing postnatal depression or anxiety, these conditions having a known association with excessive infant crying.

\section{Intervention}

All primary studies which had evaluated relevant interventions, using either qualitative or quantitative methods, were included.

Studies investigating the use of relevant measures of crying but not an intervention were excluded. Protocols for trials of interventions were excluded, as these did not evaluate the intervention concerned.

\section{Methodological quality}

Methodological quality of studies was not assessed, as the aim of the review was to identify the range of published material.

\section{Publication type/status}

All relevant studies, regardless of publication status were included.

Due to time limitations, articles not available in English were excluded. Literature published before June 2011 was excluded to avoid duplication of the evidence already reviewed by Douglas and Hill (2011). However, we included an intervention programme evaluated in Fisher et al. (2010) which met our criteria but was omitted by Douglas and Hill (2011).

\section{Search strategy}

During early December 2014, the following databases were searched: MEDLINE, PsycINFO, CINAHL, Web of Science, the Cochrane 
Database of Systematic Reviews and DARE. In addition, grey literature was searched via the OpenGrey database.

Search terms were identified pertaining to four key aspects of the review question: babies/infants; parents; crying/distress; and parental distress, support and coping. These terms were applied to each database, with a slightly modified search process in OpenGrey due the database's limitations.

\section{Selection}

Retrieved references were reviewed in a number of stages. First, all titles were evaluated against the inclusion and exclusion criteria by two team members, with titles being included for further review where at least one team member considered them relevant. In the second stage, abstracts for all included references were obtained where possible, and these were then reviewed by two team members. Where abstracts could not be obtained, a decision regarding inclusion was made on the basis of available information. Finally, the full text of the remaining papers was obtained where possible, and these were then evaluated by two researchers as before. Disagreements were resolved by a third team member at all stages.

\section{Results}

The results of the literature search are shown in Figure A1. Following removal of duplicates, 18468 potentially relevant records were identified. Once title and abstract screening were completed, 657
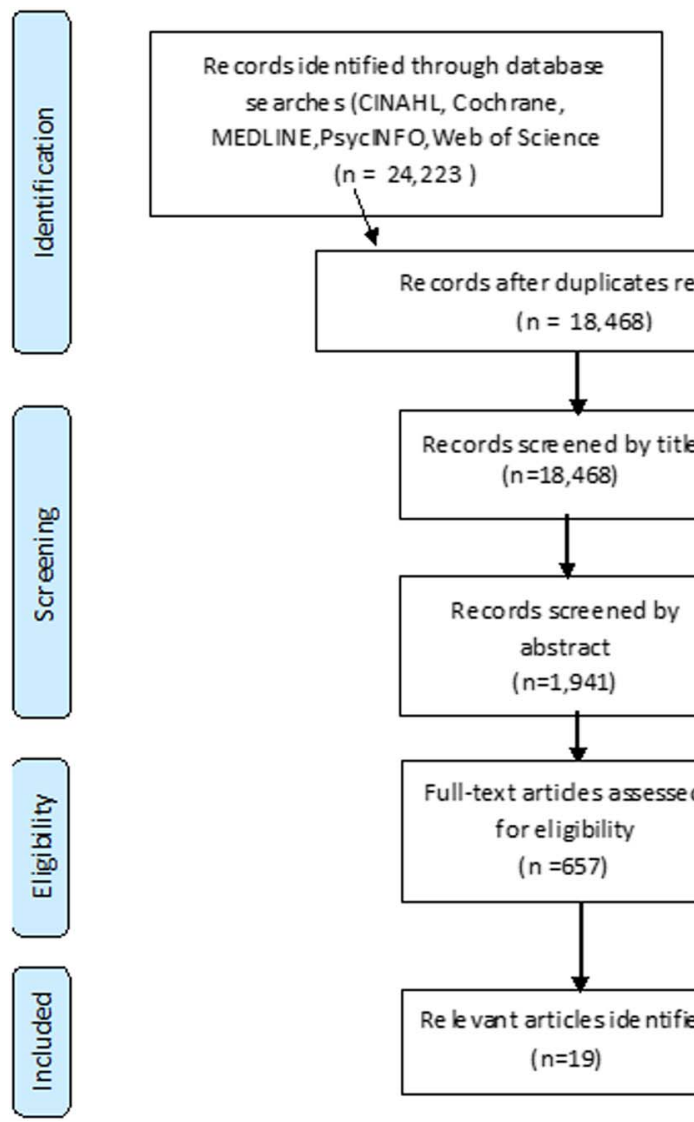

Re cords after duplicates remove d

$$
\text { ( } n=18,468)
$$
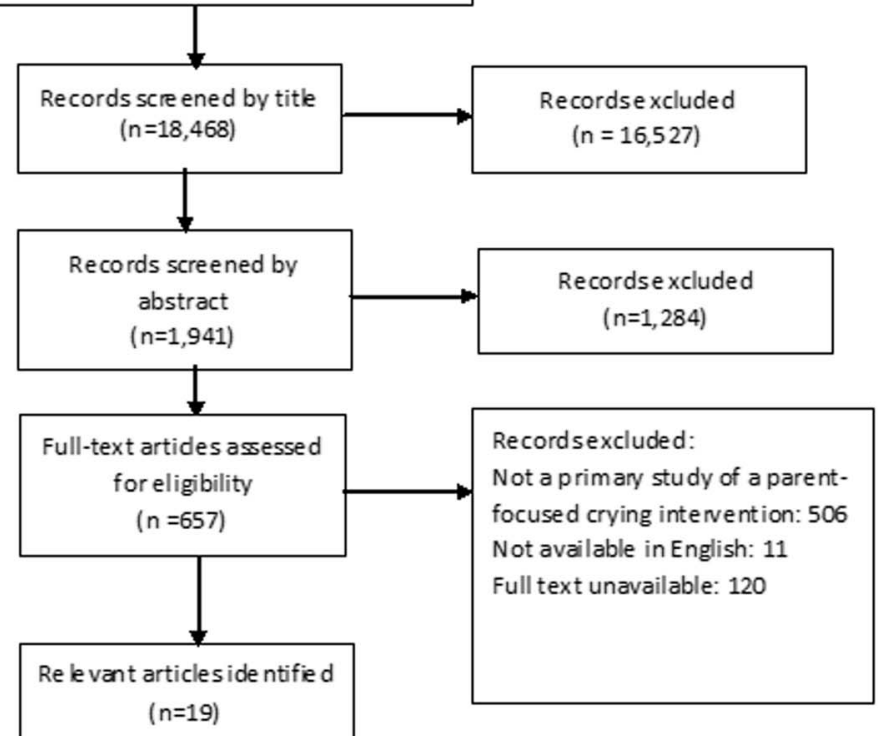

Figure A1 Results of the literature review process 
records remained to be assessed for eligibility. Upon review, it was found that whilst many articles contained information relating to excessive crying, they did not meet the review criteria. These included studies considering factors which may contribute to the crying, and parents' experiences of a crying baby. Others explored interventions not specifically targeting support for parents with crying babies, focusing instead on maternal mental health or directly attempting to treat the baby's crying. Once these were excluded, a total of 19 relevant articles remained.

The included articles identified a total of 11 different interventions (more than one paper having been published in relation to some interventions). These interventions were reviewed in order to consider their appropriateness within the context of this study using the following criteria:

- intervention materials available in a published and exportable form;

- delivery costs which allowed potential adoption of the intervention within the NHS;

- at least provisional evidence of effectiveness;

As a result of this process, four interventions were selected as shown in Table A1. The relevant organisations were contacted to gain permission for the materials to be shown and reviewed in the focus groups.

\section{Identifying evidence for interventions to support} parents experiencing postpartum distress

As well as identifying example support packages, the literature review aimed to review evidence for interventions found effective in supporting parental coping in general during the postpartum period. This decision was based on the premise that, since infant crying can be viewed as a stressor, its impact on parents would be due partly to how parents evaluated and coped with it and, consequently to parents' underlying resources, vulnerabilities and circumstances. Using the same search
Table A1 Example support materials shown to the focus group parents

\begin{tabular}{|c|c|c|}
\hline Name & Origin & Format \\
\hline $\begin{array}{l}\text { Coping with } \\
\text { Crying }\end{array}$ & UK & $\begin{array}{l}\text { Film and website aimed at } \\
\text { preventing parents from } \\
\text { harming baby due to crying. } \\
\text { Includes videos of parents and } \\
\text { experts discussing their } \\
\text { experiences and advice, and } \\
\text { one specifically highlighting the } \\
\text { risks from shaken baby } \\
\text { syndrome }\end{array}$ \\
\hline Cry Baby & Australia & $\begin{array}{l}\text { Web-based resource for parents } \\
\text { with babies with crying or sleep } \\
\text { problems. Presented in visual, } \\
\text { written and audio format, with } \\
\text { downloadable checklists and } \\
\text { tips (shown in focus groups) }\end{array}$ \\
\hline $\begin{array}{c}\text { PURPLE } \\
\text { Crying }\end{array}$ & $\begin{array}{l}\text { Canada/ } \\
\text { USA }\end{array}$ & $\begin{array}{l}\text { Website with accompanying } \\
\text { DVD (DVD not shown in focus } \\
\text { groups) aimed at providing } \\
\text { parents with information about } \\
\text { crying and preventing parents } \\
\text { from harming baby due to } \\
\text { crying. Includes text on a range } \\
\text { of relevant topics, plus short } \\
\text { videos of experts and role- } \\
\text { played scenarios }\end{array}$ \\
\hline $\begin{array}{l}\text { What Were } \\
\text { We Thinking }\end{array}$ & Australia & $\begin{array}{l}\text { Website and workbook (sample } \\
\text { pages shown in focus groups), } \\
\text { as part of a course aimed at } \\
\text { supporting new parents to cope } \\
\text { with and negotiate their } \\
\text { changed roles and } \\
\text { responsibilities }\end{array}$ \\
\hline
\end{tabular}

strategies to identify relevant research, this literature review highlighted the existence of multiple randomised-controlled trials recommending the use of CBT programmes for this purpose. As these findings were also supported by UK National Institute for Health \& Care Excellence (NICE) guidelines (NICE, 2009; 2014) this was considered sufficient evidence for this study. 